\title{
Freezing and Thawing Durability of Ultra High Strength Concrete
}

\author{
Jesus Muro-Villanueva ${ }^{1}$, Craig M. Newtson ${ }^{1}$, Brad D. Weldon ${ }^{1}$, David V. Jauregui ${ }^{1}$ and Srinivas Allena ${ }^{2}$ \\ 1. Civil Engineering Department, New Mexico State University, Las Cruces NM 88003, USA \\ 2. Civil and Environmental Engineering Department, Washington State University, Richland WA 99354, USA
}

\begin{abstract}
Resistance to freezing and thawing of two UHSC (ultra high strength concrete) mixtures was evaluated in accordance with ASTM C 666 Procedure A. The two mixtures (plain and fiber reinforced) were developed using materials local to southern New Mexico, USA. Three different curing regimens were investigated for the mixture with fibers and one curing regimen was studied for the mixture without fibers. All curing regimens included $24 \mathrm{~h}$ of ambient curing followed by four days of wet curing at $50{ }^{\circ} \mathrm{C}$, and then two days dry curing at $200{ }^{\circ} \mathrm{C}$. At an age of seven days, one batch of fiber reinforced specimens was air cured at ambient conditions for the following six days and then placed in a water bath at $4.4{ }^{\circ} \mathrm{C}$ for $24 \mathrm{~h}$ prior to initiating freezing and thawing cycles. The second batch was air cured from day seven to day 12 , and then wet cured for one day at $23{ }^{\circ} \mathrm{C}$ prior to being placed in the $4.4{ }^{\circ} \mathrm{C}$ water bath. The final batch was wet cured at $23{ }^{\circ} \mathrm{C}$ from the seventh day to an age of 13 days and then placed in the $4.4{ }^{\circ} \mathrm{C}$ water bath. The mixture with no fibers was air cured from the seventh day to an age of 12 days and then wet cured for one day at $23{ }^{\circ} \mathrm{C}$ prior to being placed in the $4.4{ }^{\circ} \mathrm{C}$ water bath. Higher moisture levels during curing produced greater initial dynamic elastic modulus values and durability factors at the end of the freezing and thawing tests, with the greatest durability factor being 87.5. Steel fibers were observed to improve both compressive strength and durability factor for UHSC.
\end{abstract}

Key words: Ultra high strength, freezing and thawing, durability, dynamic elastic modulus, quality factor.

\section{Introduction}

UHSC (ultra high strength concrete) is an advanced fiber reinforced composite material, characterized by compressive strengths greater than $140 \mathrm{MPa}$ and flexural strengths greater than $10 \mathrm{MPa}$ at 28 days [1]. UHSC is produced with a high cementitious materials content and a water-to-cementitious materials ratio $(w / c m)$ that is typically less than 0.25 . Additionally, the use of silica fume and HRWRA (high range water reducing admixtures) along with pre-setting pressure and post-setting heat treatments have been used to produce high density concrete [1, 2]. A dense microstructure results in very high compressive strengths, including values greater than $200 \mathrm{MPa}$ [3]. Along with the increase in strength, UHSC mixtures

Corresponding author: Craig M. Newtson, Ph.D., research fields: concrete materials, reuse/recycling of materials, concrete shrinkage, concrete durability, ultra-high performance concrete and nondestructive evaluation of concrete. E-mail: newtson@nmsu.edu. may need to exhibit greater durability to justify the high cost of the material. However, since UHSC is not air-entrained, its ability to withstand cycles of freezing and thawing is questionable and should be investigated.

This paper presents results from freezing and thawing tests conducted on two UHSC mixtures to ensure that UHSC without air entrainment would prove to be durable. The mixtures used in this study were developed by Allena and Newtson [1] using materials local to southern New Mexico, USA. Use of local materials is an improvement in the sustainability of UHSC over pre-packaged, commercially available UHSC products because they offer substantial cost savings. However, the chemical and physical requirements for local materials are not as strict as for commercial products. Additionally, no air-entraining admixture is used in the UHSC mixtures. Consequently, it is even more important to assess the durability of UHSC produced with local materials to 
determine whether or not it is adequate.

\section{Background}

\subsection{ASTM C 666 Procedure A}

ASTM C 666 assesses concrete resistance to freezing and thawing by subjecting concrete specimens to rapid repeated freezing and thawing cycles under laboratory conditions. The specimens are molded beams that are cured for 14 days prior to testing. On the last day of curing, the specimens are subjected to a $24 \mathrm{~h}$ conditioning period in a $4.4{ }^{\circ} \mathrm{C}$ water bath. After the conditioning period, the specimens are subjected to freezing and thawing cycles that are approximately $4 \mathrm{~h}$ in duration.

At intervals not to exceed 36 cycles, the specimens are removed from the freezing chamber during the thawed portion of the cycle for dynamic elastic modulus testing. Fundamental transverse frequency (used to compute dynamic elastic modulus), length and mass are measured. Testing of the specimens continues until each of the beams has been subjected to at least 300 cycles of freezing and thawing, or until the dynamic modulus of elasticity decreases to $60 \%$ of its initial value or less.

\subsection{Dynamic Elastic Modulus}

Testing procedures for determining dynamic elastic modulus are specified in ASTM C 215. To determine the dynamic elastic modulus, concrete prisms are excited over a wide range of frequencies using an impact hammer or a transducer to identify the frequency at which the maximum amplitude occurs. The frequency at which the maximum amplitude occurs is the resonant frequency. The concrete specimen is generally assumed to be a single-degree-of-freedom system, for which the resonant frequency is referred to as the fundamental frequency. The fundamental frequency is used to compute dynamic elastic modulus, $E_{D}$, with the following equation:

$$
E_{D}=C m \omega_{r}^{2}
$$

where, $C$ is a constant that accounts for Poisson's ratio and the geometry of the specimen, $m$ is the mass of the specimen and $\omega_{r}$ is the measured fundamental frequency.

When ASTM C 215 is used to monitor deteriorating concrete, it is common to present results in terms of the relative dynamic modulus, computed as follows:

$$
R D M=\frac{E_{n}}{E_{o}}(100)
$$

where, $R D M$ is the relative dynamic modulus after $n$ cycles of freezing and thawing, $E_{n}$ is the dynamic elastic modulus after $n$ cycles, and $E_{o}$ is the dynamic elastic modulus at zero cycles of freezing and thawing. After completion of freezing and thawing cycles, a durability factor, $D F$, can be computed as:

$$
D F=\frac{R D M \cdot N}{M}
$$

where, $N$ is the number of cycles imposed, and $M$ is the specified number of cycles (usually 300).

\subsection{Quality Factor}

When concrete is subjected to cycles of freezing and thawing, degradation can be caused by distributed microcracking in the concrete [4]. This microcracking results in increased damping in addition to a decrease in dynamic elastic modulus. Damping can be quantified by the quality factor, $Q$, which can be determined from a frequency response curve. An example of a frequency response curve is plotted in Fig. 1. Since a wide range of frequencies are excited by the impact method, amplitudes at frequencies other than the fundamental frequency are known. This allows the quality factor, to be computed with the following relationship:

$$
Q=\frac{\omega_{r}}{\omega_{2}-\omega_{1}}
$$

where, $\omega_{1}$ and $\omega_{2}$ are the frequencies on either side of $\omega_{r}$ with amplitudes equal to $70.7 \%$ of the amplitude of $\omega_{r}$ (Fig. 1). Quality factor is inversely proportional to the damping ratio, $\zeta$, as shown in the following equation:

$$
Q=\frac{1}{2 \zeta}
$$




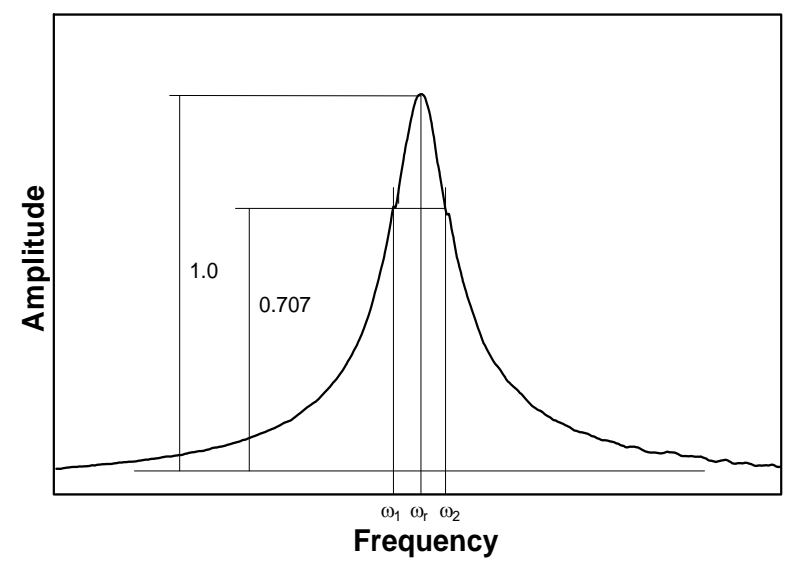

Fig. 1 Frequency response curve.

Relative quality factor, calculated with an expression similar to Eq. (2), has been shown to be useful for describing deterioration caused by freezing and thawing $[4,5]$.

\subsection{Ultra High Strength Concrete}

Shaheen et al. [6] conducted a study on UHSC mixtures with seven day compressive strengths up to $500 \mathrm{MPa}$. The mixtures included different carbon fibers contents, presetting pressures, curing processes and heat-treating temperatures. Results from ASTM C 666 Procedure A testing revealed that UHSC mixtures with carbon fibers had durability factors of 100 , which represents no decrease in dynamic elastic modulus after testing. Conversely, mixtures without fibers tended to show a decrease in dynamic elastic modulus [6].

Other freezing and thawing studies $[7,8]$ have used various temperature ranges, specimen dimensions and cycle durations. Results showed relative dynamic modulus of 100 after up to 800 cycles of freezing and thawing. The percentage of mass lost during testing on both studies was extremely low or zero. It was concluded that the UHSC mixture provided excellent frost resistance.

Graybeal [9] presented results from ASTM C 666 Procedure A testing that showed that various steam curing regimens as well as duration of exposure to each treatment greatly influence UHSC durability factors. Mixtures exposed to longer wet curing regimens produced greater initial dynamic elastic modulus, but tended to produce lower durability factors.

Studies on curing of high performance concrete mixtures have shown that the microstructure of the surface concrete can be disturbed by the curing method, resulting in a reduction in durability [10]. High performance concrete mixtures with silica fume are more sensitive to curing methods than mixtures without silica fume due to microcracking caused by desiccation [10]. Hasni et al. [10] presented results that show that high performance concrete mixtures with high silica fume contents have less microcracking when cured at a higher relative humidity.

Non air-entrained concrete mixtures along with low water to binder ratios may have satisfactory durability against freezing and thawing if a compressive strength of at least $24 \mathrm{MPa}$ is achieved prior to the first freezing cycle [10]. The use of a low water to binder ratio ensures that all of the mixing water combines with the cementitious material, resulting in a concrete with low permeability that prevents critical saturation of the paste. Therefore, the presence of an air void system in the concrete is not essential [11].

\section{Experimental Methods}

The two UHSC mixtures used in this study were developed by Allena and Newtson [1]. Compressive strengths obtained from $51 \mathrm{~mm}$ cubes at 28 days were 170.3 $\mathrm{MPa}$ for the fiber reinforced UHSC mixture and 159.9 MPa for the plain UHSC mixture.

\subsection{Materials}

Type I-II portland cement, silica fume and local alluvial sand from Las Cruces, New Mexico, USA were used to produce the UHSC mixtures in this research. Steel fibers with a length of $13 \mathrm{~mm}$ were used to improve ductility. Workability was obtained using a polycarboxylate-based HRWRA (Glenium 


\section{NS from BASF).}

The local sand had a specific gravity of 2.53 and an absorption of $1.2 \%$. Table 1 presents the grain size distribution of the sand. The sand was sieved to retain particles between ASTM \#30 and \#200 (600 $\mu \mathrm{m}$ and $75 \mu \mathrm{m})$ sieves. The sand was first passed through a No. $30(600 \mu \mathrm{m})$ sieve and then washed over a No. 200 (75 $\mu \mathrm{m})$ sieve. The sand was then oven dried and placed in an air tight container to ensure $0 \%$ moisture content.

\subsection{Concrete Mixtures}

Two different concrete mixtures (with and without fibers) were tested for freezing and thawing resistance according to ASTM C 666 and for compressive strength according to BS 1881. Saturated surface-dry mixture proportions for both mixtures are presented in Table 2.

\subsection{Mixing and Curing}

The dry constituents of each mixture were mixed for 15 min using a $20 \mathrm{~L}$ pan mixer. Then, $75 \%$ of the water was added and mixing continued for $5 \mathrm{~min}$. The HRWRA was then added, and mixing continued for another $5 \mathrm{~min}$. Next the remaining $25 \%$ of the water was added and mixing continued for another $10 \mathrm{~min}$. The final step in the mixing process was to add the steel fibers and mix for another $5 \mathrm{~min}$.

Slump measurements were performed for both UHSC mixtures in accordance with ASTM C 143. The fiber reinforced UHSC mixture produced a slump of $235 \mathrm{~mm}$ while the plain UHSC mixture had a slump of $180 \mathrm{~mm}$.

Freezing and thawing specimens were prepared according to ASTM C 192. Each prism was prepared in two layers. Consolidation was achieved by rodding each layer every $1,400 \mathrm{~mm}^{2}$ of the surface using a 16 $\mathrm{mm}$ rod. After specimens were rodded, they were externally vibrated using a table vibrator to improve consolidation. Theoretical densities for the UHSC mixtures were $2,286 \mathrm{~kg} / \mathrm{m}^{3}$ for fiber reinforced UHSC and $2,205 \mathrm{~kg} / \mathrm{m}^{3}$ for plain UHSC. Density of the hardened UHSC was measured at $24 \mathrm{~h}$ and was found to be $2,343 \mathrm{~kg} / \mathrm{m}^{3}$ for fiber reinforced UHSC and $2,261 \mathrm{~kg} / \mathrm{m}^{3}$ for plain UHSC. These values were increases of $2.49 \%$ and $2.55 \%$ from the theoretical density for the fiber reinforced and plain UHSC mixtures, respectively.

A total of four $76 \mathrm{~mm} \times 102 \mathrm{~mm} \times 406 \mathrm{~mm}$ prisms were produced from each batch for ASTM C 666 testing. The fiber reinforced UHSC mixture was used to produce a total of 12 prisms (three batches) while the plain UHSC mixture was used to produce four prisms. In addition to the prisms, four $102 \mathrm{~mm}$ and eight $51 \mathrm{~mm}$ cubes were prepared from each batch for compressive strength testing at 14 days.

The specimens were cured for 14 days prior to testing. During the first seven days, the curing regimen was the same for all of the batches. The specimens remained in their molds for $24 \mathrm{~h}$ at room temperature $25{ }^{\circ} \mathrm{C}$. After demolding, the specimens were heat cured in a waterbath at $50{ }^{\circ} \mathrm{C}$ for the following four days. Then, they were dry cured in an oven at $200{ }^{\circ} \mathrm{C}$ for two days. Curing at these elevated temperatures to an age of seven days was necessary to achieve the desired strength.

Table 1 Grain size distribution of sand.

\begin{tabular}{lll}
\hline Sieve No. & Sieve size $(\mu \mathrm{m})$ & Passing $(\%)$ \\
\hline 30 & 600 & 100.0 \\
50 & 300 & 31.7 \\
100 & 150 & 2.9 \\
200 & 75 & 0.0 \\
\hline
\end{tabular}

Table 2 Saturated surface-dry mixture proportions of UHSC mixtures.

\begin{tabular}{lllllllll}
\hline Mixture & $\begin{array}{l}\text { Cement } \\
\left(\mathrm{kg} / \mathrm{m}^{3}\right)\end{array}$ & $\begin{array}{l}\text { Silica fume } \\
\left(\mathrm{kg} / \mathrm{m}^{3}\right)\end{array}$ & $\begin{array}{l}\text { Fine sand } \\
\left(\mathrm{kg} / \mathrm{m}^{3}\right)\end{array}$ & $\begin{array}{l}\text { Steel fibers } \\
\left(\mathrm{kg} / \mathrm{m}^{3}\right)\end{array}$ & $\begin{array}{l}\text { Water } \\
\left(\mathrm{kg} / \mathrm{m}^{3}\right)\end{array}$ & $\begin{array}{l}\text { HRWRA } \\
\left(1 / \mathrm{m}^{3}\right)\end{array}$ & $\mathrm{w} / \mathrm{c}$ & $\mathrm{w} / \mathrm{cm}$ \\
\hline Fiber reinforced & 890 & 222 & 799 & 119 & 222 & 29.6 & 0.25 & 0.20 \\
Plain & 890 & 222 & 837 & - & 222 & 29.6 & 0.25 & 0.20 \\
\hline
\end{tabular}


From an age of seven days to an age of 14 days, three different curing regimens were investigated to identify practices that might improve UHSC durability. The three curing regimens that seemed most likely to be used in practice were:

Regimen 1: Specimens were air cured for six days at room temperature, $25{ }^{\circ} \mathrm{C}$, followed by $24 \mathrm{~h}$ of conditioning in a water bath at $4.4{ }^{\circ} \mathrm{C}$;

Regimen 2: Specimens were air cured for five days at $25{ }^{\circ} \mathrm{C}$, followed by one day of moist curing at $23{ }^{\circ} \mathrm{C}$, and then $24 \mathrm{~h}$ conditioning in a water bath at $4.4^{\circ} \mathrm{C}$;

Regimen 3: Specimens were moist cured for six days at $23{ }^{\circ} \mathrm{C}$, followed by $24 \mathrm{~h}$ of conditioning in a water bath at $4.4^{\circ} \mathrm{C}$.

Regimens 1 through 3 were used on the fiber reinforced mixture, but only regimen 2 was used for the plain UHSC mixture.

\subsection{Testing Program}

Cube specimens were tested for compressive strength at 14 days according to BS 1881. Prism specimens were tested for resistance to freezing and thawing according to ASTM C 666 Procedure A. In accordance with this testing method, a 3-h 31-min cycle was selected. One full cycle of freezing and thawing consisted of rapid temperature decrease from $4.4{ }^{\circ} \mathrm{C}$ to $-17.8{ }^{\circ} \mathrm{C}$ in approximately $2 \mathrm{~h} 20 \mathrm{~min}$. The temperature was then held constant for 8 min before raising the temperature back to $4.4{ }^{\circ} \mathrm{C}$ in $53 \mathrm{~min}$. The temperature was then held constant at $4.4{ }^{\circ} \mathrm{C}$ for 10 min. Testing was conducted during this $10 \mathrm{~min}$ window.

The specimens were subjected to 300 cycles of freezing and thawing (or less when the relative dynamic elastic modulus of a specimen dropped below 60). Length, mass and fundamental frequency (to compute dynamic elastic modulus) measurements were taken at intervals no greater than 36 cycles. Distilled water was used in the conditioning water bath and for immersion of the specimens during freezing and thawing cycles.

\section{Results and Discussion}

\subsection{Compressive Strength}

Compressive strengths at 14 days for the fiber reinforced and plain UHSC mixtures are presented in Table 3. These values are less than the 28 day strengths (170.3 MPa for fiber reinforced UHSC and 159.9 MPa for plain UHSC) reported by Allena and Newtson [1] because testing was conducted at 14 days. Fiber reinforced UHSC mixtures produced greater 14 day strengths than the plain UHSC mixture for batches cured under the same regimen. The increase in compressive strength caused by the fibers was approximately $11 \%$ for $51 \mathrm{~mm}$ cubes and $17 \%$ for 102 mm cubes. It was observed that batches with wetter curing regimens between ages of seven and 14 days did not produce greater strength.

\subsection{Freezing and Thawing}

Initial dynamic elastic modulus results are also presented in Table 3. Mixtures exposed to longer periods of wet curing produced greater initial dynamic elastic modulus values than mixtures with drier curing regimens. Curing regimen 3 produced a $25 \%$ greater initial dynamic elastic modulus than curing regimen 1

Table 3 Average compressive strength and initial dynamic elastic modulus values.

\begin{tabular}{lllll}
\hline \multirow{2}{*}{ Mixture } & Curing regimen & \multicolumn{2}{c}{ Compressive strength (MPa) } & Initial dynamic elastic \\
\cline { 2 - 4 } & & $102 \mathrm{~mm}$ cubes & $51 \mathrm{~mm}$ cubes & 32.4 \\
\hline Fiber reinforced & 1 & 130.2 & 141.1 & 34.8 \\
& 2 & 136.0 & 146.6 & 40.8 \\
& 3 & 132.8 & 137.1 & 34.4 \\
\hline
\end{tabular}


for the fiber reinforced UHSC. Fiber content did not appear to influence initial values of dynamic elastic modulus since the fiber reinforced and plain UHSC mixtures had similar values when curing regimen 2 was used.

Figs. 2-4 show the relative dynamic modulus values versus cycles of freezing and thawing for individual specimens from each of the three curing regimens for the fiber reinforced UHSC mixture. Results show a consistent decline in relative dynamic modulus throughout the duration of the testing. However, specimens with drier curing regimens experienced a more rapid decline in relative dynamic modulus than specimens with wetter curing regimens. Wetter curing regimens also seemed to produce less variation between the relative dynamic modulus of specimens within the same group.

Fig. 5 presents relative dynamic modulus values versus cycles of freezing and thawing for the plain UHSC mixture. This mixture was only tested under curing regimen 2 . The initial dynamic elastic modulus values for this mixture were nearly the same as those from the fiber reinforced UHSC mixture cured under regimen 2. However, relative dynamic modulus of the plain UHSC mixture declined more abruptly than the relative dynamic modulus of the fiber reinforced specimens cured according to regimen 2. Average values for each of the four mixture and curing regimen combinations investigated in this study are provided in Fig. 6. As observed in Figs. 2-5, relative dynamic modulus declined more rapidly for drier curing regimens, as well as in the mixture without steel fibers. This behavior is consistent with observations by Graybeal [9] on specimens with wet versus dry curing regimens.

The fiber reinforced mixture with curing regimen 1 reached an average relative dynamic modulus of 60 at cycle 196. According to ASTM C 666 it is considered to have failed. The average relative dynamic modulus of the remaining mixtures did not drop below 60 before completing the testing period.
For the plain and fiber reinforced specimens cured according to regimen 2, degradation of the plain mixture occurred more rapidly than in the fiber reinforced mixture. It was observed that the use of steel fibers not only provided greater compressive

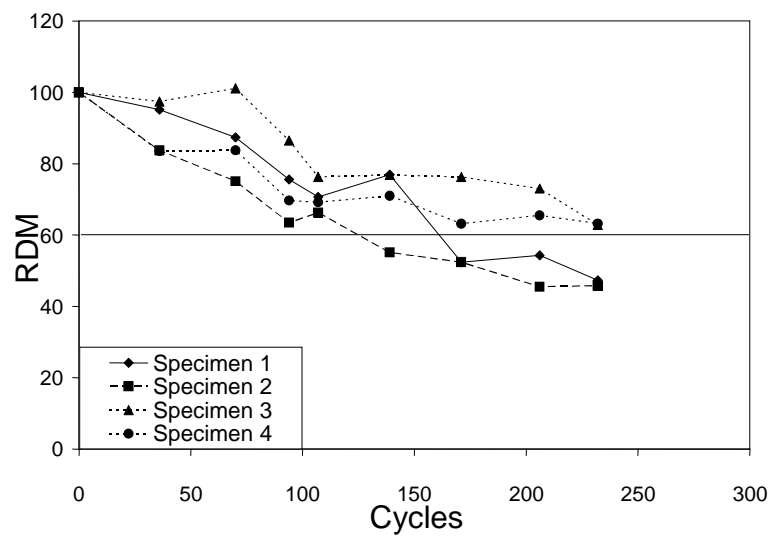

Fig. 2 Relative dynamic modulus for fiber reinforced UHSC cured according to regimen 1.

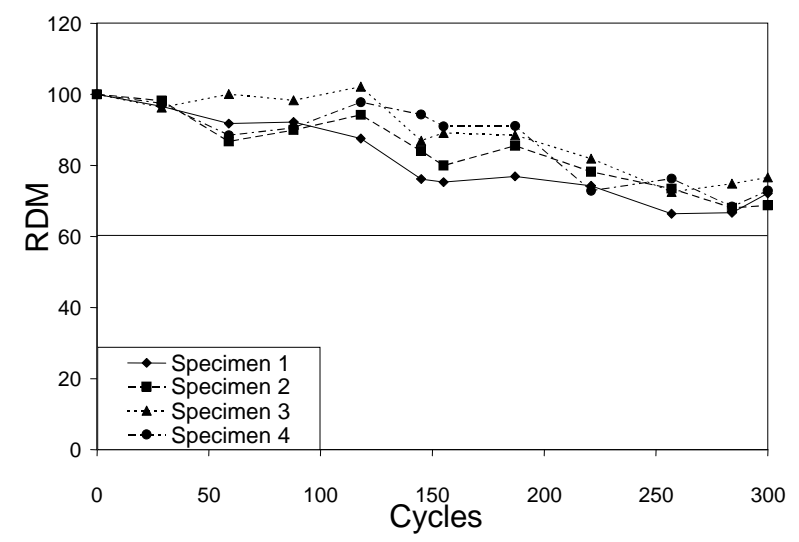

Fig. 3 Relative dynamic modulus for fiber reinforced UHSC cured according to regimen 2.

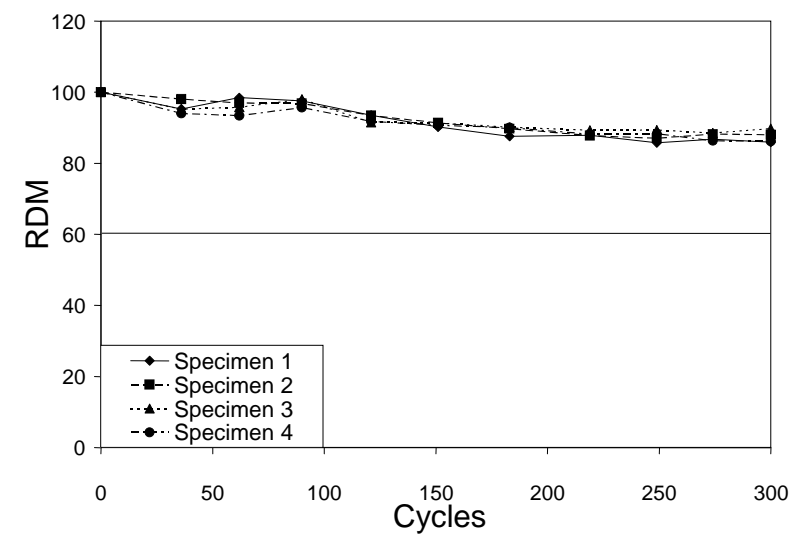

Fig. 4 Relative dynamic modulus for fiber reinforced UHSC cured according to regimen 3. 


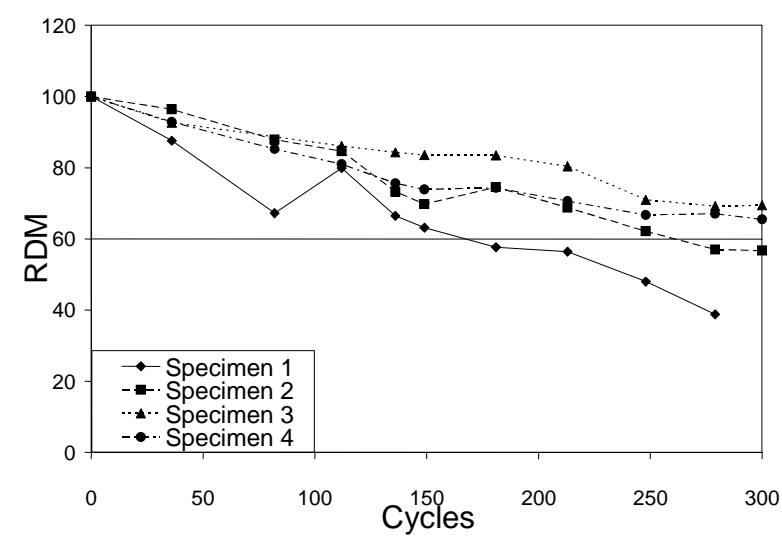

Fig. 5 Relative dynamic elastic modulus for plain UHSC cured according to regimen 2 .

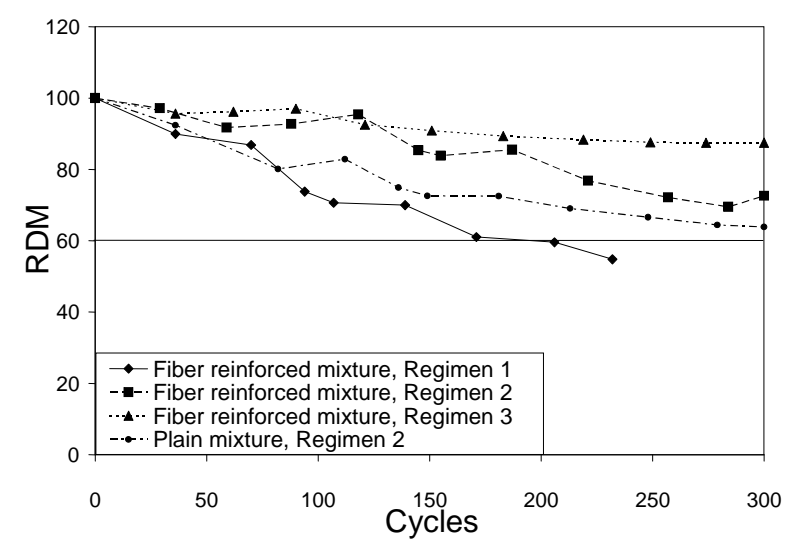

Fig. 6 Average relative dynamic modulus for all batches.

strength, but also improved the resistance to freezing and thawing by restraining the expansion of the microcracks.

Fig. 7 presents the average relative quality factor values versus cycles of freezing and thawing for the four combinations of mixtures and curing regimens. It was observed that the relative quality factor dropped below 60 within 20 to 50 cycles for all of the combinations.

As with decreases in relative dynamic modulus, decreases in relative quality factor were more rapid for specimens with drier curing regimens and for the mixture without steel fibers. The most abrupt decline in quality factor was observed for specimens subjected to curing regimen 1 . This abrupt decline coincided with an early failure (based on relative dynamic modulus) of the specimens cured using that regimen.
Table 4 presents a summary of the average durability factors for the four combinations of mixtures and curing regimens. The durability factors represent the relative dynamic modulus values at the end of the freezing and thawing cycles (Fig. 6). Durability factors were greater for wetter curing regimens. Curing regimen 3 produced the greatest durability factor (87.5). Although only four specimens were tested for each batch, all of the average durability factors were significantly different $(95 \%$ confidence) except the plain mixture and the fiber reinforced mixture cured under regimen 1.

Minor scaling occurred at approximately 100 cycles for all specimens, whereas spalling of corners only occurred on the fiber reinforced UHSC mixture with curing regimen 1 and on the plain UHSC mixture. Elongation of prisms was relatively constant throughout the duration of testing. Elongation values at the end of testing ranged from $0.18 \%$ to $0.22 \%$.

Mass of the freezing and thawing specimens increased as water filled microcracks caused by freezing and thawing. Fig. 8 shows the average relative mass change for the specimens.

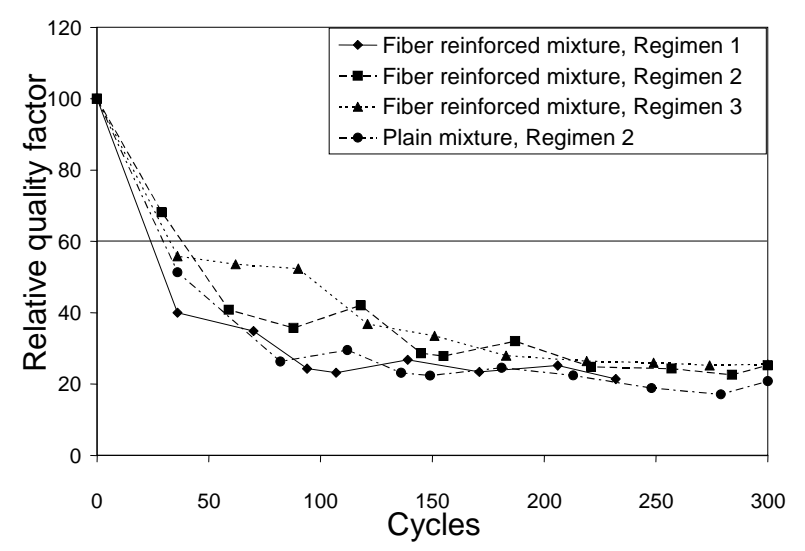

Fig. 7 Average relative quality factor for all batches.

Table 4 Average durability factors.

\begin{tabular}{lll}
\hline Mixture & Curing regimen & Durability factor \\
\hline Fiber reinforced & 1 & 39.7 \\
& 2 & 72.6 \\
& 3 & 87.5 \\
Plain & 2 & 55.1 \\
\hline
\end{tabular}




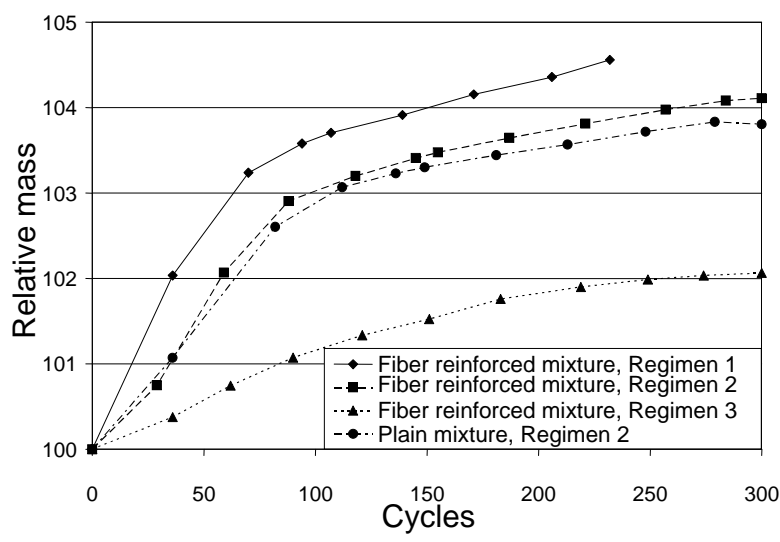

Fig. 8 Relative mass for all batches.

The wettest curing regimen (regimen 3) resulted in substantially less mass gain than the drier curing regimens.

\subsection{Modulus of Rupture}

Modulus of rupture for the UHSC mixtures was determined using ASTM C 78 testing procedures. This test was performed using a simple beam with third-point loading.

Allena and Newtson [1] reported the seven day modulus of rupture strengths of undamaged specimens $(76 \mathrm{~mm} \times 102 \mathrm{~mm} \times 406 \mathrm{~mm})$ to be $17.5 \mathrm{MPa}$ for fiber reinforced UHSC and $10.9 \mathrm{MPa}$ for plain UHSC. At the end of freezing and thawing cycles conducted in the present work, the deteriorated test specimens were tested for modulus of rupture. Results from this testing are presented in Table 5. All of the specimens lost at least $60 \%$ of the 7 -day flexural strength. The fiber reinforced mixture cured according to regimen 2 provided greater flexural strength after completion of 300 cycles of freezing and thawing than the plain UHSC mixture. However, the percentage decrease in modulus of rupture from the 7-day strengths given in Allena and Newtson [1] were comparable for the plain and fiber reinforced UHSC specimens cured according to regimen 2. Specimens exposed to wetter curing conditions also retained greater modulus of rupture values.

Greater durability factors corresponded to greater modulus of rupture values at the end of testing for results
Table 5 Modulus of rupture results after ASTM C 666 testing.

\begin{tabular}{llll}
\hline Mixture & $\begin{array}{l}\text { Curing } \\
\text { regimen }\end{array}$ & $\begin{array}{l}\text { Modulus of } \\
\text { rupture (MPa) }\end{array}$ & $\begin{array}{l}\text { Percent of } \\
\text { 7-day strength }\end{array}$ \\
\hline Fiber & 1 & 3.75 & 21.4 \\
Reinforced & 2 & 5.18 & 29.6 \\
& 3 & 5.90 & 33.7 \\
Plain & 2 & 2.61 & 23.9 \\
\hline
\end{tabular}

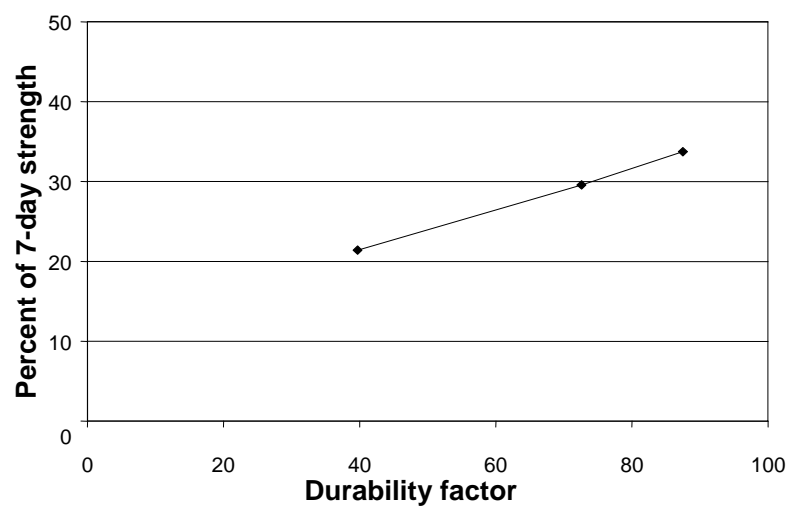

Fig. 9 Percentage of 7-day flexural strength versus durability factor for fiber reinforced UHSC mixtures.

obtained within the fiber reinforced UHSC mixture. Fig. 9 illustrates the correlation between durability factor and retained modulus of rupture percentage, showing that the relationship is nearly linear.

\section{Conclusions}

The effects of the different curing methods on compressive strength were observed to be negligible. Conversely, initial dynamic elastic modulus values for concrete specimens with wetter curing conditions were greater than those from specimens with drier curing conditions. The presence of fibers did not appear to influence initial dynamic elastic modulus.

Providing more moisture in the last seven days of curing following the heat treatment increased the durability of UHSC. It was observed that any increase in curing moisture resulted in improved durability factors. Wetter curing also resulted in less mass gain during ASTM C 666 testing, greater modulus of rupture at the end of the freezing and thawing cycles, and less variation in relative dynamic modulus between specimens from the same group. Durability 
of UHSC exposed to freezing and thawing was also improved by the use of steel fibers.

Quality factors decreased sharply almost immediately after freezing and thawing cycles were initiated for all specimens. The quality factors produced the same trends observed for relative dynamic modulus but served as an earlier indicator of deterioration. However, it is difficult to provide a good correlation between quality factor and relative dynamic modulus degradation because the decline in quality factor was so rapid.

Modulus of rupture decreased more than relative dynamic modulus. In fact, even when durability factor was acceptable (greater than 60) modulus of rupture still decreased by more than $60 \%$ from the seven day strength values.

\section{References}

[1] S. Allena, C.M. Newtson, Ultra high strength concrete mixtures using local materials, in: International Concrete Sustainability Conference, National Ready Mixed Concrete Association, Tempe, AZ, Apr. 2010, http://www.concretetechnologyforum.org/2010CSCProcee dings (accessed July 9, 2011)

[2] J.C. Scheydt, H.S. Müller, Microstructure of ultra high performance concrete (UHPC) and its impact on durability, in: The 3rd International Symposium on UHPC and Nanotechnology for High Performance Construction Materials, Kassel, Germany, 2012, pp. 349-356.

[3] M. Cheyrezy, P. Richard, Composition of reactive powder concrete, Cement and Concrete Research 25 (7) (1995)
1501-1511.

[4] E. Vokes, S. Clarke, E. Janssen, Damping measurements for nondestructive evaluation of concrete beams, in: Proceedings of International RILEM Workshop on Resistance of Concrete to Freezing and Thawing with or Without Deicing Chemicals, UK, 1997, pp. 1-10.

[5] J. Muro-Villanueva, C.M. Newtson, B.D. Weldon, D.V. Jauregui, S. Allena, Freezing and thawing durability of ultra high strength concrete, in: International Congress on Durability of Concrete, Trondheim, Norway, 2012.

[6] E. Shaheen, N.J. Shrive, Optimization of mechanical properties and durability of reactive powder concrete, ACI Materials Journal 103 (6) (2006) 444-451.

[7] W.Y. Ji, M.Z. An, G.P. Yan, J.M. Wang, Study on Reactive Powder Concrete Used in Sidewalk System of the Qinghai-Tibet Railway Bridge, 2007, http://www.cptechcenter.org/publications/sustainable/jireac tive.pdf (accessed July 11, 2011).

[8] J. Piérard, B. Dooms, N. Cauberg, Evaluation of durability parameters of UHPC using accelerated lab tests, in: The 3rd International Symposium on UHPC and Nanotechnology for High Performance Construction Materials, Kassel, Germany, 2012, pp. 371-376.

[9] B. Graybeal, Material Property Characterization of Ultra-High Performance Concrete, Federal Highway Administration report No. FHWA-HRT-06-103, McLean, VA, 2006.

[10] L. Hasni, J.L. Gallias, M. Salomon, Influence of the curing method on the durability of high performance concretes, durability of concrete, in: Third International Conference, Nice, France, 1994, pp. 131-155.

[11] B. Mather, How to make concrete that will be immune to the effects of freezing and thawing, International Concrete Research \& Information Portal 122 (1990) 1-18. 